Article

\title{
The Effect of Wind Power Installations on Coastal Tourism
}

\author{
Meredith Blaydes Lilley, Jeremy Firestone * and Willett Kempton \\ Center for Carbon-free Power Integration, College of Earth, Ocean, and Environment, University of \\ Delaware, Newark, DE, 19716, USA; E-Mails: mblaydes@udel.edu (M.B.L.); \\ willett@udel.edu (W.K.) \\ * Author to whom correspondence should be addressed; E-Mail: jf@udel.edu; \\ Tel.: +1-302-831-0228; Fax: +1-302-831-6838.
}

Received: 10 October 2009 / Accepted: 10 December 2009 / Published: 8 January 2010

\begin{abstract}
We surveyed more than 1,000 randomly sampled, out-of-state tourists at Delaware, USA beaches in 2007. After providing respondents with wind turbine project photo-simulations at several distances, we inquired about the effect development would have on visitation. Approximately one-quarter stated that they would switch beaches if an offshore wind project was located $10 \mathrm{~km}$ from the coast, with avoidance diminishing with greater distance from shore. Stated avoidance is less than: avoidance with a fossil fuel power plant located the same distance inland; attraction to a beach with offshore wind turbines; and the percentage stating they would likely pay to take a boat tour.
\end{abstract}

Keywords: wind power; offshore; tourism; beach; contingent behavior

\section{Introduction}

Beginning in 1980 with a "few experimental turbines" [1] and expanding to more than 25,000 MW of installed capacity [2], the domestic wind power industry has exceeded even the most optimistic expectations held in the early 1990s for its potential growth [1]. During the past four years, the United States has led the world in installed wind energy capacity [3-5].

Offshore wind is of particular interest today in the Eastern US, because it is a very large resource close to urban load centers that lack other large, cost-effective renewable resources [6]. Despite offshore wind power's technical viability, proven in 19 years' experience in Europe, the US has yet to commission an offshore wind project. The delay is due in part to anticipated public objection to any 
offshore project, following the widely publicized Cape Wind proposal, with its well-funded and politically connected public opposition [7-9]. Nevertheless, other states have begun moving forward with offshore wind development. Texas first approved offshore wind development in 2005, and 2008 was a breakthrough year, with Delaware, Rhode Island, and New Jersey all accepting bids for offshore wind power. In Delaware specifically, Bluewater Wind, LLC has recently entered into a power purchase agreement (PPA) with the regulated utility, Delmarva Power \& Light, for the purchase and sale of energy from an offshore wind farm to be constructed and operated offshore by Bluewater. The wind turbines would be located approximately $22 \mathrm{~km}$ from the Delaware coast.

\subsection{The Local Economic Importance of Coastal Tourism}

One oft-claimed, but as yet unsubstantiated, criticism of wind power is its perceived negative impact on local tourism. For example, a 2005 study found that a sizeable percentage of Cape Cod residents (more than 40\%) believe the Cape Wind project will negatively impact local tourism [7]. However, as described below, this effect has not been observed at European offshore wind sites, and indeed, evidence suggests that offshore wind power actually boosts local economies by drawing increased numbers of visitors.

Any effect on local tourism must be distinguished from the effect of offshore wind farms on tourism more generally. While a wind farm might decrease tourism in the locality, tourism would presumably increase in another location, and although overall revenues would not necessarily change, there would be a loss in consumer surplus among those that switch beaches [10]. In future work, we may examine that issue; here we are focused on the local effects - that is, the effect on the adjacent community and the state.

Greater clarity as to the potential impact of offshore wind power on beach tourism revenues would be valuable given that beach tourism contributes substantially to the economies of numerous US coastal states. Indeed, beaches are the nation's lead tourist destination, and due to this tremendous popularity, coastal states garner approximately $85 \%$ of tourism-related revenues [11]. In Delaware's economy, tourism plays a critical role. Expenditures from out-of-state, US visitors to Delaware reached $\$ 2.4$ billion in 2006, comprising 75\% of the state's total tourism sales [12]. Also in 2006, economic activity in the Delaware travel and tourism sector created approximately 38,000 jobs, both direct and indirect, accounting for $8.7 \%$ of total state employment and ranking tourism as the state's $5^{\text {th }}$ largest employer [12].

Moreover, the majority of these tourism revenue and employment gains are attributable to Delaware's beach region, with beach tourism expenditures in 2004-\$627 millionrepresenting $40.6 \%$ of total tourism expenditures [13]. In 2001, Delaware's ocean beaches received an estimated 4.8 million person trips, generating $\$ 665$ million in expenditures and \$409 million in consumer surplus [14]. In 2004, the majority of out-of-state trip expenditures in Delaware's beach region fell in the lodging sector (as compared to the food, shopping, entertainment, and transportation sectors) with tourists spending \$296 million (47\% of total expenditures) on accommodation [13].

As an economic comparison, Bluewater indicated that a $600 \mathrm{MW}$ wind project off the coast of Delaware would employ 500 workers for two years during the construction phase and 80 on an ongoing basis. Proponents of wind power therefore point to the employment benefits of projects as an 
economic plus for the local economy. On the other hand, there might be local job losses if tourists are diverted out of state, but a $2 \%$ drop in tourism, for example, would not necessarily result in a $2 \%$ drop in local employment. Moreover, although a $600 \mathrm{MW}$ project would generate approximately \$200 million per year (\$2007) in electricity sales, much of the revenues would likely be utilized to pay off loans that would have been put toward the purchase of wind turbines, which would mostly likely have been manufactured in Europe.

\subsection{Research Objectives}

State and local governments in the US, and national and local governments in the European Union, are typically concerned about job retention and economic policies. Public policy decisions require good data on the negative effects of offshore wind development and potential economic losses as well as economic gains. The purpose of this study is thus to improve the estimates of the likely effects (positive and negative) of wind development on local tourism. Although this study examines this question in the context of wind power development off of the Delaware coast, it may more broadly shed light on the expected economic effects of wind power development at other tourism-dependent sites, given the dearth of analysis of this question at land-based, let alone offshore, installations.

The findings complement those of a 2006 mail survey eliciting the same views and opinions on offshore wind power held by Delaware residents [15] and thus in tandem the two present a more complete picture of the implications of such development. This article will compare the findings of this out-of-state tourist survey with those of its counterpart Delaware resident survey.

\section{Previous Studies Examining Tourism and Offshore Wind Power}

Studies of observed behavior in response to offshore wind turbines reveal either no effect or a positive effect on tourism. However, given climate and tourist expectations in adjacent communities, as described below, the applicability of these studies to the US experience is somewhat limited. Surveys examining expected behavior in response to hypothetical or proposed offshore wind turbines have more mixed results, with a number showing expected increases in tourism, others little to no effect, and one indicating a potential decline in tourism. Unfortunately, a number of these studies have not employed rigorous scientific methods [16].

Given that the only offshore wind installations in the world are in European waters, it is fitting to first assess post-construction tourism effects there. Empirical information in this regard is limited to two case studies, Horns Rev in Denmark and Scroby Sands in England. The discussion then turns to an examination of surveys conducted in mainland Europe, the United Kingdom, and the United States to better elucidate the potential tourism effects (positive and negative) of offshore wind turbines that may be constructed in the future.

\subsection{Observed Changes in Tourism Behavior - the European Experience}

Denmark's Horns Rev, one of the world's largest offshore wind farms, is situated in the North Sea 14 to $20 \mathrm{~km}$ [17] off the coast of the Blavand Strand, a scenic, miles-long sweep of public beach [18]. 
Before construction of Horns Rev, local authorities and businesses opposed it, fearing declines in tourism, a chief component of the local economy. Kuehn [19], however, found neither a decrease in the community's tourism levels nor any reduction in the price of summerhouse rentals one year following construction. The absence of any effect on tourism is thought to have largely led to a noticeable movement away from opposition towards acceptance among the residential population [19]. Further, experiences at Scroby Sands, one of the UK's first utility-scale offshore wind farms, suggest a positive impact on tourism. There, the on-site, educational visitor center welcomed 30,000 visitors within its first six months of opening [20].

While the finding of no overall effect on tourism in Denmark is promising for the wind industry, some have questioned its applicability to tourist sites in the United Kingdom and the United States. According to Cook [21], Denmark is a small, fairly developed and urbanized country with a high density of land-based wind turbines. Tourists visiting Denmark's coastal area do not visit for the "wilderness experience and unspoilt nature of the country" [21] (p.9). However, visitors to Scotland, according to groups concerned about the effect of wind farms on tourism, do visit for that reason. Moreover, in the European Union, areas with high numbers of coastal tourists, such as resorts in the Mediterranean, have "generally not been targeted for offshore wind development" [22] (p.98); conversely in the United States, offshore wind installations have been proposed at sites that experience high levels of recreational and tourism use (including Cape Cod; Block Island, Rhode Island; southern Delaware; and Atlantic City, New Jersey) [22]. Thus, wind farms off the US Atlantic coastal region might be expected to generate more objections on aesthetic grounds than those sited off the coast from less populated areas, with ties to non-tourist, commercial uses such as those found in Denmark [23].

\subsection{Studies on Potential Changes in Tourism Behavior}

Studies on tourist attitudes, perceptions and potential changes in behavior have been conducted in both Europe and the United States. A survey in Germany, prior to the construction of any offshore wind farms, found general acceptance by tourists and residents, provided that the wind farms were not sited too close to the coastline. Offshore wind turbines were also favored over those onshore [24], a trend also uncovered by Ladenburg [25]. Further, studies in Sweden show higher levels of acceptance among local residents than among tourists [26,27]. A 2006 survey likewise found a higher percentage of Delaware residents (84\%) than tourists, sampled herein, reporting they would be likely to visit a new beach to see an offshore wind farm [8].

The debate regarding the effect of wind farms on tourism revenues has grown contentious, with inconclusive evidence to confirm the claims of either side. Dalton et al. [28] surveyed tourists at hotels in Australia, asking for their views on renewable energy and showing them on- and offshore wind farm simulations, among other options. Only $40 \%$ responded favorably to the offshore simulation, yet the simulated turbines appear both unrealistic (the turbines in the offshore wind farm simulation appear elongated and otherwise disproportionate, as compared to those in the onshore simulation) and much closer to shore (within five kilometers) than most in existence today [8]. Conversely, MORI, a respected research organization in Scotland, polled over 300 visitors in a tourism-dependent town for their opinions on local, land-based wind farms. Fifty-five percent of the sample reported a positive to completely positive impression, whereas only $8 \%$ reported a negative one. Moreover, $80 \%$ of those 
surveyed stated interest in visiting an educational center at a wind farm during their trip. Yet, while widely cited as evidence for wind power's lack of adverse impacts on tourism, even in areas treasured for their beautiful scenery, the results of this study have been discounted as biased toward wind developers, who paid MORI to conduct the research. According to Strachan et al. [29] "broader evidence" is needed to conclude that wind farms are a source of economic development.

Additional studies carried out in the UK and in the US provide further insight into the effect of wind farms on tourism levels and, in turn, revenues. Yet, in all of them, respondents were not randomly chosen. The NFO WorldGroup's interviews of visitors to Wales reveal that the large majority is generally positively disposed toward wind farms. Upon viewing simulations of offshore wind farms, negative responses decreased with increasing distance from shore, an intuitive finding. Interestingly, tourists reported a distinct preference (83\%) for siting wind farms offshore rather than onshore, largely due to the perception of reduced aesthetic and environmental impacts in offshore locations. This finding may indicate a low likelihood of offshore wind farms deterring tourists in Wales. The study also uncovered some evidence of wind-farm attraction of tourists, with $21 \%$ reporting that wind facilities would be "an added attraction... in popular tourist areas" [30] (p.4,18-19). Mills and Rosen [31] uncovered similar results in a non-random convenience poll of New Jersey beachgoers, reporting that $14.6 \%$ would be more likely to visit a beach with a wind farm ten kilometers offshore, whereas only $9.2 \%$ would be less likely. Last, among tourists at onshore wind sites in England, Aitchison [32] found little effect on tourism, with slightly higher numbers of visitors reporting they would be drawn to the wind farm (7.2\%) rather than deterred from it $(6.1 \%)$.

In sum, evidence supports both sides of the tourism debate, but geographic differences between existing and proposed offshore wind sites in the European Union and the United States confound comparability, and few scientific studies have been conducted. With regard to the effect of offshore wind farms on local tourism activity and revenues, the jury is thus still out $[17,27,29,33]$.

\section{Methods}

\subsection{Survey Development}

Survey design commenced in February 2007. The survey instrument underwent sixteen iterations over the course of its development. Duplication of some questions from a previous study of Delaware residents [34] allowed for comparison across the two surveys. Protocols for developing and administering the survey drew from Dillman's Tailored Design Method [35].

The survey instrument was pretested with 91 respondents at one Delaware beach on June 21 and July 2, 2007. Pretesting proved critical for improving question wording, clarity, and order, and for refining formatting and length.

The final survey instrument, printed as a booklet, had five sections. The first section elicited general opinions of both onshore and offshore wind power. The second primarily investigated how beach visitation behavior might change if wind turbines were added to the seascape. These contingent behavior questions are discussed further below. The third section tested knowledge of the impacts of carbon dioxide emissions on the coastal environment, as well as perceptions of wind power's potential contribution to mitigating climate change. The fourth section asked about respondents' current trip, 
including duration, lodging distance from shore, and lodging expenditures. The final section elicited demographic data.

Professionally simulated photos of wind farms were employed, as they provide concrete visual examples for respondents to more realistically estimate their reactions to potential changes in the ocean view, an important consideration when undertaking surveys on perceptions and opinions of wind projects. The simulations in this study may visually overstate the impact of offshore turbines on the ocean view and thus produce conservative results. First, respondents received simulations of turbines that encompassed the entire ocean horizon (see the supplementary materials for the simulations), a framing that exaggerates the extent to which they would be visible. In a recent study, Global Insight [36] noted that at about five kilometers off the coast, a wind farm would occupy only $45 \%$ of the ocean vista, and at 10 kilometers, only $22.5 \%$. Second, Bishop and Miller [37] found that perceived visual impacts decrease with decreasing wind turbine contrast against the horizon (during hazy or cloudy versus clear weather conditions, or under back versus front lighting). They also uncovered a significant difference in perceived visual impacts between simulations of moving versus stationary blades, with the latter consistently generating more negative responses. Our simulations show a wide field of turbines, are front-lighted, and as still photos, show stationary blades, all factors that might increase negative reactions.

\subsection{Contingent Behavior}

A primary focus of the research was to gain an understanding of how tourist beach choice would be affected by the presence of wind turbines, or a fossil power plant, as a function of the distance of those facilities from the beach. Beach choice could be measured using either stated preference (contingent valuation or $\mathrm{CV}$, and contingent behavior or $\mathrm{CB}$ ) or revealed preference techniques. Because we are examining behavior in response to a hypothetical wind farm, and considering the absence of offshore wind farms in the US, we use reported or stated choices of how an individual is likely to behave as opposed to an individual's actual (revealed) choices made after the development of a wind farm [38]. While validity studies, which compare, inter alia, respondents' observed behavior post-policy with their stated behavior pre-policy, have been more commonly conducted with CV studies, Grijalva et al. [38] conducted a validity test with a CB study. They found that surveyed individuals did "not appear to overstate changes in trip behavior when presented with hypothetical questions" about access restrictions to a site they visited [38] (p.413).

In contrast to contingent valuation (CV) studies, which elicit willingness to pay estimates, $\mathrm{CB}$ studies derive demand behavior estimates for a nonmarket good [39]. Because we are interested in how changes in an attribute of a good (in this case, the placement of a wind farm) may affect tourism expenditures, CB was employed. Given that out-of-state tourists generate 75\% of Delaware's tourism revenues, the majority of which are ascribed to the state's beach region [12-13], reported beach visitation in this study serves as a proxy for local tourism revenues.

With CB, proper research design and methods - which include carefully designing the survey questions to elicit truthful responses, pretesting the survey instrument, and randomly selecting respondents - are essential for obtaining sound data [40]. We further discuss the methods we employed in the next section. 


\subsection{Sampling Strategy and Pretesting}

Delaware's compact, Atlantic Ocean coastline extends only about $40 \mathrm{~km}$ [41] yet has a wide crosssection of beaches. Some are highly developed (with oceanfronts lined with hotels, restaurants, boardwalks and shops) whereas others are state parks with more natural surroundings (only a simple shower and changing area, a snack bar, and lifeguards). To plan the full survey sample, we conducted beach reconnaissance trips on May 15, 2007 and July 2, 2007. Criteria recorded included the size and availability of parking as well as the presence of other beach amenities such as bathhouses and lifeguards. We also informally interviewed local persons with knowledge of beach tourism — state park officials, representatives from local chambers of commerce, town managers, and the tourism director at the Delaware Economic Development Office (DEDO). Based on information gathered, we stratified the sample to include: developed beach sites at three coastal towns-Rehoboth Beach (and its boardwalk), Dewey Beach, and Bethany Beach (and its boardwalk); and beaches at three state parks - Cape Henlopen State Park, Delaware Seashore State Park, and Fenwick Island State Park.

Based on pretests, we systematically intercepted beachgoers using a geographic-transect method to obtain a probability sample. This process involved walking along the beach parallel to the shore. At regular, predetermined intervals (depending on the density of beachgoers) the surveyor would turn to face the ocean and walk in a straight line to the water. The closest individuals (one per group) within six feet of that transect were then asked two screening questions: whether they were out-of-state residents; and, if qualifying age was in doubt, whether they were at least eighteen years old. Eligible adults who agreed to participate were handed the survey on a clipboard with laminated offshore wind simulation pictures. Refusals and acceptances were tallied. This selection process was systematically repeated along the length of the beach. On boardwalks, we intercepted individuals seated on benches in the most highly trafficked area-where the boardwalk and the town center coincide-always selecting the adult seated to one pre-determined side (for example, the person furthest to the right). Both the geographic-transect method for beaches and the bench selection process for boardwalks proved to be minimally disruptive. These approaches, along with the advantage of communicating in person with unoccupied beachgoers on vacation, allowed for a high response rate, noted below.

\subsection{Implementation, Response Rates, and Weighting}

A total of ten survey researchers took part in the data collection during two trips. The first spanned three weekdays and two weekend days (from Wednesday, July $18^{\text {th }}$ through Sunday, July $22^{\text {nd }}$ ); the second occurred on the weekend of August $4^{\text {th }}$ and $5^{\text {th }}$. We sampled in July and August, during the expected height of the Delaware beach tourist season (given school vacations and the fact that the highest air temperatures are experienced during those months). Leisure and business travel visitor trends in Sussex County, which includes Delaware's main state beaches, provide further support for the selection of July and August [42]. At each beach site, sampling took place over two days, one weekday and one weekend day. Each boardwalk location was sampled on one weekend day.

Of the 1,716 adult beachgoers approached, 386 were Delaware residents and thus ineligible to take the survey. Of the 1,330 eligible, 1,076 agreed to participate, yielding an overall response rate of $81 \%$; the response rate was lower on the boardwalks, where people are more transient, although still robust 
(Table 1). We collected a minimum of 100 surveys at each beach, with larger numbers at the two locations with the most visitors, Rehoboth and Bethany beaches; we collected slightly fewer surveys at both boardwalks. The survey responses were coded and entered into a database. In total, more than half of the surveys (with 55 data points apiece) were double-checked and corrected, as needed (with an error rate of less than $0.1 \%$ found).

We weighted each sampled beach according to its beach visitation rate [43] in relation to the total visitation of all sampled beaches. The Bethany and Rehoboth boardwalk locations were grouped with their adjacent beach. The more often a tourist visited a sampled beach, the greater the probability of he or she had of being selected to participate in the survey. As a result, for a portion of the analysis, we evaluated the data in two ways: (1) weighting solely by beach location and (2) weighting by both beach location and the inverse of the number of days a respondent reported to have visited Delaware beaches in the last 12 months. The first better accounts for visitor-days by allowing more frequent visitors to be sampled more often. The latter better samples tourists on an individual basis, regardless of how often they visit the beach.

Table 1. Surveys completed and response rates by sampling location.

\begin{tabular}{lcc}
\hline Sampling location & \# Completed surveys & Response rate \\
\hline Rehoboth Beach & 173 & $81.6 \%$ \\
Rehoboth Boardwalk & 74 & $61.7 \%$ \\
Bethany Beach & 190 & $87.2 \%$ \\
Bethany Boardwalk & 72 & $72.0 \%$ \\
Dewey Beach & 165 & $79.7 \%$ \\
Cape Henlopen State Park & 145 & $81.9 \%$ \\
Fenwick Island State Park & 116 & $87.2 \%$ \\
Delaware Seashore State Park & 141 & $86.5 \%$ \\
TOTAL & 1,076 & $80.9 \%$ \\
\hline
\end{tabular}

\section{Results and Discussion}

This section reports: (1) demographic and trip characteristics; (2) wind power attitudes and perceptions; (3) reported changes in beach visitation, contingent upon a wind farm at varying distances from shore or the presence of an inland fossil fuel power plant; and (4) potential economic development associated with attraction to a beach with a wind farm. We also discuss the significant factors influencing beach choice, uncovered through contingent behavior modeling.

\subsection{Demographic and Trip Characteristics}

Of the 1,040 out-of-state respondents who provided their state or country of primary residence, $99.2 \%$ are from the United States. Over two-thirds visited from three adjacent states: Pennsylvania (39.5\%), Maryland (28.5\%) and Virginia (10.9\%). Lower percentages traveled to Delaware beaches from New York (5.9\%), New Jersey (4.0\%), the District of Columbia (2.3\%) and 
Ohio (1.2\%). The remaining $7.8 \%$ of US respondents traveled from 25 other states, each comprising less than $1 \%$ of the total.

Table 2 displays demographic and trip characteristics of the sample population. The majority of respondents are female (58.5\%) with the median education level being a bachelor's degree. The mean age is 46 , while median household income falls within the range of $\$ 75,000$ to $\$ 99,999$. Further, $17.2 \%$ own property in a Delaware beach community as a second home. Compared to the population of Delaware residents [8] the sampled tourists are similarly educated, but on average younger and wealthier.

When asked about their previous visits for pleasure or recreation to Delaware beaches, respondents reported visiting an average of 19.4 total days in the past 12 months. On their present trip, those staying only for the weekend comprised $16 \%$, and day-trippers $12 \%$, of the sample. The $88 \%$ who reported staying overnight in Delaware stayed an average of 7.4 nights. They spent slightly more than $\$ 1,100$ for lodging, which was on average five kilometers from the beach. More visitors (20.9\%) rented a beach house than any other type of lodging (for example, motel, campground, etc.).

Table 2. Sample characteristics (means, unless indicated otherwise).

\begin{tabular}{lc}
\hline \multicolumn{1}{c}{ Variables } & Sample values \\
\hline Age & Individual attributes \\
Male tourist & 46 \\
Median education & $41.5 \%$ \\
Median household income & Bachelor's degree* \\
Own property in Delaware & $\$ 75,000$ to $\$ 99,999$ \\
\hline & $17.2 \%$ \\
\hline Days visited Delaware beach in past year \\
Staying for weekend & 19.4 \\
Staying overnight & $15.5 \%$ \\
Nights in Delaware & $87.6 \%$ \\
Number in lodging group & 7.4 \\
Trip lodging cost & 4.8 \\
Lodging distance from shore & $\$ 1,106$ \\
\hline
\end{tabular}

* The education scale ranges from one (completed elementary or middle school) to seven (graduate or professional degree).

For further background information on what out-of-state beachgoers expect from their beach experience, we asked respondents to rank the desirability of different beach features or amenities. The means for these beach features are ranked in order from most to least desirable $(4=$ most desirable; $0=$ least desirable) in Table 3. Here and in the remaining presentation of the data descriptively, the results have been weighted by both location and beach visitation. 
Table 3. Mean desirability of beach features $(n=953)$.

\begin{tabular}{lc}
\hline Beach feature & Mean desirability \\
\hline Adequate parking & 3.5 \\
Wide sandy beach & 3.4 \\
Lifeguards & 3.3 \\
Bath house facilities & 3.2 \\
Boardwalk & 3.1 \\
Undeveloped, natural beach & 3.1 \\
Big waves & 2.6 \\
Fishing & 2.1 \\
Vehicle access on the beach & 1.9 \\
Wind farm 10 km from shore & 1.8 \\
Many people & 1.5 \\
\hline
\end{tabular}

\subsection{Wind Power Attitudes and Perceptions}

As illustrated in Table 4, 85\% of respondents perceive wind power in general as either positive or very positive. Conversely, less than $1 \%$ holds a negative to very negative view of wind power. When asked about the effect of wind turbines on the "environment" (without ascribing a particular meaning to the term such as wildlife, health or climate) $80 \%$ similarly reported a positive effect. But when asked about the effect on landscape appearance, more than half are neutral, with equal percentages positive or negative.

Table 4. Attitude toward and perceived effects of wind power.

\begin{tabular}{lccc}
\hline Response & $\begin{array}{c}\text { General } \\
\text { attitude } \\
(\mathbf{n = 1 , 0 3 6 )}\end{array}$ & $\begin{array}{c}\text { Effect of wind turbines } \\
\text { on the environment } \\
(\mathbf{n = 1 , 0 3 5 )}\end{array}$ & $\begin{array}{c}\text { Effect of turbines on } \\
\text { appearance of landscape } \\
(\mathbf{n}=\mathbf{1 , 0 3 5})\end{array}$ \\
\hline Very positive & $45.4 \%$ & $37.6 \%$ & $4.3 \%$ \\
Positive & $39.3 \%$ & $41.9 \%$ & $17.4 \%$ \\
Neutral & $14.9 \%$ & $17.3 \%$ & $56.5 \%$ \\
Negative & $0.4 \%$ & $3.1 \%$ & $20.0 \%$ \\
Very negative & $0.0 \%$ & $0.0 \%$ & $1.7 \%$ \\
\hline
\end{tabular}

The overall positive attitude toward wind power also applies to sea-based wind power, as displayed in Table 5. Only $2.6 \%$ of visitors stated that it should be prohibited. In contrast, eighty-six percent stated that ocean siting of wind turbines should be allowed in appropriate circumstances (with "appropriate" being undefined), or encouraged and promoted. This level of support from out-of-state beachgoers is not significantly different from that of Delaware residents who live near the ocean $(80.7 \%)$, but is significantly less than the level of support among Delaware residents statewide (91.7\%) [8]. This finding is consistent with Ladenburg [44], who observed that people who use the coastal zone more frequently - either as tourists who visit the beach often or as residents who live close to the coast - appear to associate higher visual disamenities and environmental costs with 
offshore wind farms than those who have weaker connections to coastal areas. However, we did not find statistically significant, finer gradations of support based on frequency of beach visits.

Table 5. Support to place turbines in the ocean $(n=1,034)$.

\begin{tabular}{lc}
\hline Response & Percentage \\
\hline Encouraged and promoted & $35.0 \%$ \\
Allowed in appropriate circumstances & $51.0 \%$ \\
Tolerated & $5.7 \%$ \\
Prohibited in all instances & $2.6 \%$ \\
Not sure & $5.7 \%$ \\
\hline
\end{tabular}

\subsection{Reported Changes in Beach Visitation}

\subsubsection{Descriptive Statistics}

The survey posited wind farms at different distances: $1.5 \mathrm{~km}$ from the coast, $10 \mathrm{~km}, 22 \mathrm{~km}$, and too far out to see (which we refer to here as "out of sight"). We present the results in tabular and in graphic form, Table 6 and Figure 1, respectively.

Table 6. Reported visitation at varying wind farm distances $(\mathrm{n}=983)$.

\begin{tabular}{lcccc}
\hline Respondent beach choice & $\mathbf{1 . 5} \mathbf{~ k m}$ & $\mathbf{1 0} \mathbf{~ k m}$ & $\mathbf{2 2} \mathbf{~ k m}$ & Out of sight \\
\hline Same beach & $55.3 \%$ & $73.9 \%$ & $93.7 \%$ & $99.4 \%$ \\
Different beach in Delaware & $35.0 \%$ & $18.9 \%$ & $4.3 \%$ & $0.3 \%$ \\
No Delaware beach & $9.7 \%$ & $7.2 \%$ & $2.0 \%$ & $0.3 \%$ \\
\hline
\end{tabular}

Figure 1. Reported visitation at varying wind farm distances $(\mathrm{n}=983)$.

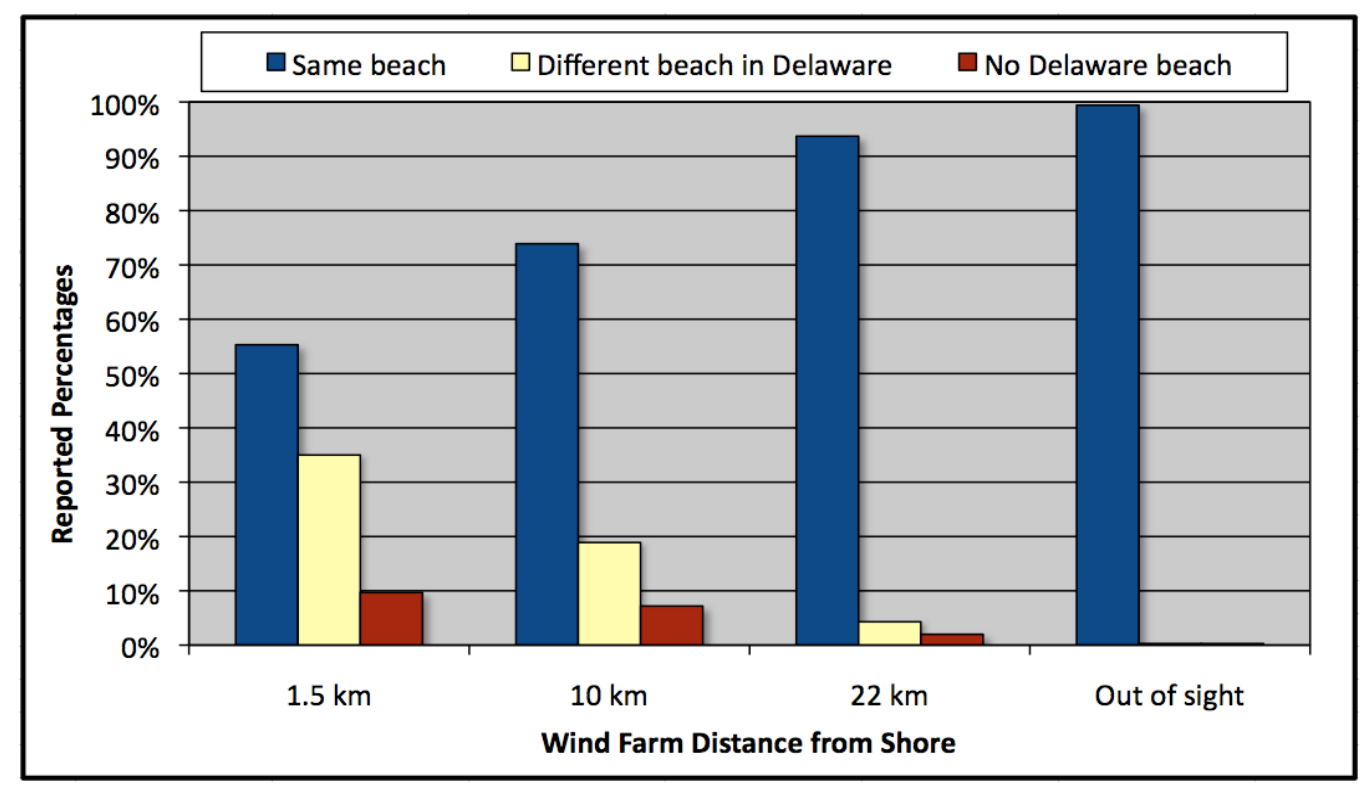

The reported loss of tourism at the closest distance $(1.5 \mathrm{~km})$ is substantial, with almost $45 \%$ stating they would switch to another Delaware beach or not go to a Delaware beach at all. With increasing 
wind farm distances from shore, however, progressively fewer respondents report diversion from Delaware beaches. These results are consistent with those of Krueger [15], and are also predictable considering that visual impact is one source of opposition to wind power [45] and that the ocean view is presumably one amenity sought by beachgoers given advertisements for and higher prices of accommodations with an ocean view. Some diversion to another beach, albeit marginal, is still reported when the turbines are "out of sight," suggesting reasons for opposing offshore wind other than visual aesthetics.

A 2006 survey asked Delaware residents a similar question regarding the potential effect of a wind farm situated $10 \mathrm{~km}$ offshore on their beachgoing behavior [8]. Here we compare responses to questions across these two surveys, which used the same visualizations, but with slightly different wording (500 versus 200 turbines; and asking respondents to recall their most recent beach visit versus the present one).

Almost identical percentages of out-of-state beachgoers (93\%) and Delaware residents (94\%) indicate that they would continue to visit a beach in Delaware if a wind farm existed $10 \mathrm{~km}$ from shore. However, a smaller percentage of out-of-state beachgoers (74\%) than Delaware residents (89\%) reported that they would have gone to the same Delaware beach. Of those saying they would either move to another beach in Delaware or to a beach in another state, a greater percentage of Delaware residents (51\%) report that they would likely switch to a different Delaware beach than out-of-state tourists (28\%) [8]. These findings make sense. First, presumably, Delaware residents are more likely to take more frequent and shorter trips to local beaches due to their closer proximity to them than out-of-state beachgoers. Typically traveling greater distances, those from out-of-state are more likely to plan less frequent, but longer trips, and may therefore be more selective when choosing their annual holiday beach location. Second, switching to non-Delaware beaches may present more of an economic hardship in terms of additional travel costs (measured in time and out-of-pocket outlays) for Delaware residents than, for example, Maryland, Pennsylvania or New Jersey residents. Third, Delaware residents also may have a sense of greater fealty to Delaware beaches than out-of-state visitors. Finally, although both residents and tourists are exposed to the perceived visual disamenity, local residents stand to benefit from employment at a nearby wind farm or from the profit-sharing venture of allowing wind turbines to operate on their property, whereas temporary residents or tourists, who tend to be financially independent of the region, do not [26,27].

For each of these beach amenity characteristics, denoted above in Table 3, we conducted a difference-of-means test between those who would go to a Delaware beach with an offshore wind farm and those who would switch to an out-of-state beach. None of the means were significantly different from each other except for the desirability of vehicle access on the beach. Those who would continue visiting a Delaware beach with an offshore wind farm value vehicle access on the beach significantly more than those who would not continue visiting a Delaware beach. This finding is reasonable; respondents who desire vehicle access understandably would be more amenable to additional uses of the coast, such as offshore wind development, compared to those looking for a more pristine beach not subject to multiple uses. Additionally, there may not be good substitutes for beaches with vehicle access in neighboring states.

Furthermore, stated visitation if there were an offshore wind farm, and the attitudes toward and perceived effects of offshore wind power (presented in Table 4) are positively and significantly 
correlated (at the $1 \%$ level) with each other. These findings are intuitive, illustrating that as wind power attitudes and perceived effects among respondents become more positive, reported visitation at Delaware beaches with offshore wind development increases as well.

Figure 2 graphs the percentage of respondents choosing "same beach" as a function of distance when wind turbines are in view. It can thus be used to predict the number of tourists who would report switching at any given distance within the range. For example, at $22 \mathrm{~km}$ offshore (the approximate distance proposed for Delaware's Bluewater Wind, LLC development) an estimated 8\% would report that they would switch to another beach if shown a similar simulated view at that distance, although a much smaller percentage ( $\sim 2 \%)$ would shift out-of-state. This estimate is high, however, because the Bluewater wind farm will be further than $22 \mathrm{~km}$ from some beaches, and indeed, will not be visible from some. According to Figure 2, an offshore wind farm constructed $16 \mathrm{~km}$ from shore would result in $17 \%$ of beachgoers visiting another beach, although again, the majority of these shifts would occur within, rather than beyond, Delaware. This estimate is likewise high, given that the data upon which it is based assumes that the wind farm would be located adjacent to each Delaware beach.

Figure 2. Acceptance of offshore wind in view.

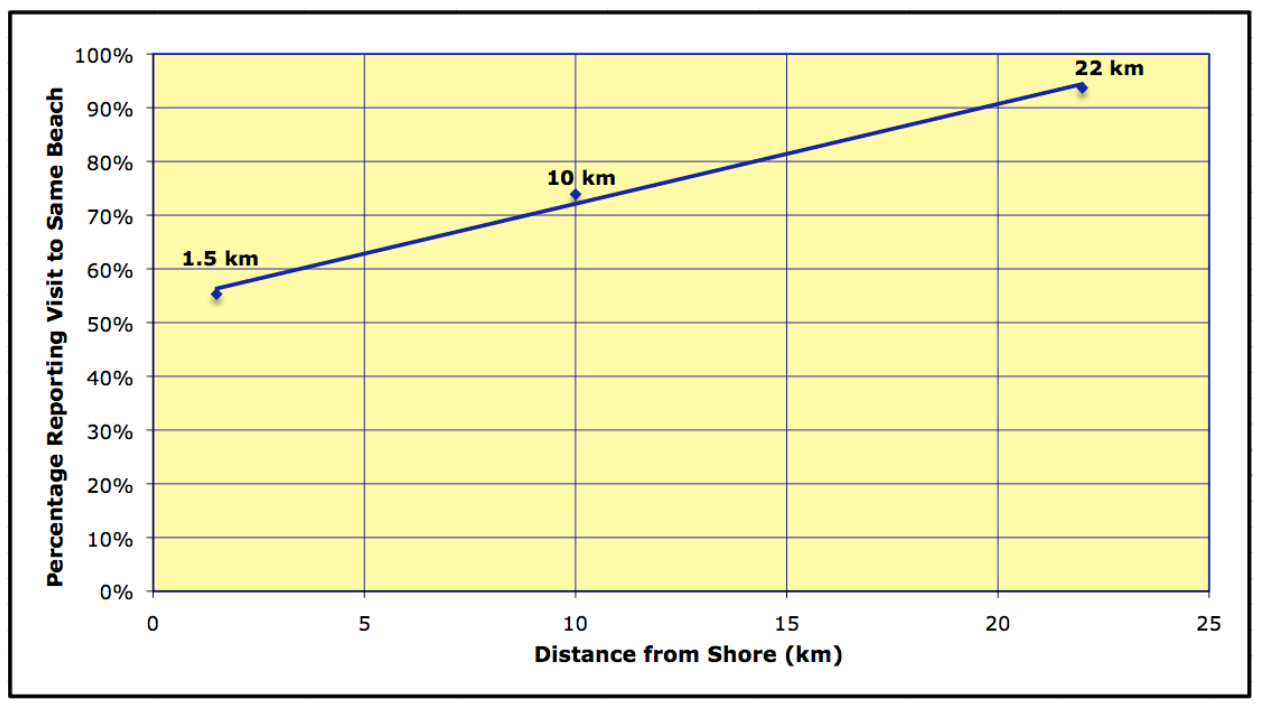

Although the surveys of Delaware residents [46] and tourists indicate that wind farms present visual disamenities, the decision of whether to locate a new wind farm cannot be made in isolation but must consider the tradeoffs among various means of generating electricity $[47,48]$. When respondents were presented with two different beach visit scenarios - (1) a wind farm located $10 \mathrm{~km}$ from shore; and (2) a coal or natural gas power plant located the same distance inland- $73.6 \%$ stated they would visit the same beach with the wind farm, whereas $61.1 \%$ stated they would visit the same beach with the coal plant. It is worth noting that a large coal power plant exists approximately $14.5 \mathrm{~km}$ from the Delaware coast [8]. Even though the wind farm would be more intrusive on the ocean view, the posited coal or natural gas power plant thus reduces visitation by $12.5 \%$ more than does the hypothetical offshore wind farm. This difference in beach avoidance is statistically significant. These results account for respondents who may have known about the nearby coal plant and chose to visit the beach anyway, whereas other beachgoers, not sampled in this survey, may have visited another beach to avoid it. Thus, the coal-plant diversion effect may be greater than $61.1 \%$. 
An alternative explanation of this inconsistency — whereby people say they would avoid a beach with a nearly coal plant, even though they were on such a beach when interviewed - is that some fraction of respondents use this type of visitation question to "vote" against various types of energy development. If the "voting" explanation is correct, then our finding can be interpreted as meaning that more people are opposed to a nearly coal plant they cannot see than are opposed to a wind development in their ocean view.

\subsubsection{Contingent Behavior Modeling}

The following multivariate logistic regression model predicts a given tourist's reported likelihood of visiting a Delaware beach with a wind farm $10 \mathrm{~km}$ from shore, based on trip-related and demographic factors. Due in part to Delaware's small coastline, state policy regarding the tourism effects of offshore wind power is likely to consider any tourism loss statewide, rather than in-state tourism losses or shifts. Thus, we model whether or not a visitor is likely to switch to an out-of-state beach. More specifically, the dependent variable is assigned a " 1 " if a tourist reported he or she is likely to visit either the same beach or another beach in Delaware and a " 0 " if otherwise. Given that there is more variation in the dependent variable at $10 \mathrm{~km}$ than at $22 \mathrm{~km}$, and $10 \mathrm{~km}$ represents a reasonable distance at which development might occur, we model this question based on responses at $10 \mathrm{~km}$. Table 7 presents the model's coefficient estimates and other regression statistics.

Table 7. Logit regression of the likelihood of visiting a Delaware beach if a 10-kilometer wind farm existed off the coast of sampled tourist destination.

\begin{tabular}{lcccc}
\hline Variable & Coefficient & Odds ratio & Standard error & p-value \\
\hline No lodging cost & -0.055 & 0.946 & 1.313 & 0.966 \\
Mean lodging cost (natural log) & -0.216 & 0.805 & 0.183 & 0.237 \\
Mean income (natural log)* & -0.923 & 0.397 & 0.508 & 0.069 \\
Own property & -0.991 & 0.371 & 0.867 & 0.253 \\
Age below30** & 2.221 & 9.215 & 0.869 & 0.011 \\
Have seen wind turbine before & 0.356 & 1.427 & 0.537 & 0.508 \\
Surveyed on a boardwalk*** & 2.298 & 9.950 & 0.842 & 0.006 \\
Surveyed at Cape Henlopen** & 2.065 & 7.889 & 0.995 & 0.038 \\
16 or 17 year old in group** & 1.238 & 3.450 & 0.620 & 0.046 \\
Constant** & 13.838 & & 5.498 & 0.012 \\
\hline \multicolumn{5}{c}{$\mathbf{N}$} \\
& Chi-square & $\mathbf{5 4 2}$ & $\mathbf{4 8 . 7 1}$ & \\
\\
& P value & $\mathbf{0 . 0 0 0 0}$ & & \\
\hline
\end{tabular}

* Significant at $10 \%$ level, ** Significant at $5 \%$ level, $* * *$ Significant at $1 \%$ level

$\dagger$ The number of observations in the model (542) is reduced largely due to unreported responses in the following variables, ranked from highest to least amount of missing data: trip cost, income, property ownership, and age.

The model fits the data well, with a likelihood ratio statistic significant at the 0.0001 level. Excluding the constant, the model has one significant variable at the $1 \%$ level, three at the $5 \%$ level, and one borderline significant at the $10 \%$ level. 
We generated histograms for expenditures (lodging cost — a proxy for trip expenditures) and income to examine whether those measures' probability distributions are more log normal or linear normal. We found lodging expenditures to be bimodal in distribution due to a large component of sampled tourists who spent no money for lodging on their beach trip. When this zero-expenditure group is excluded, the lodging-cost distribution appears log normal. Income likewise appears log normal. We therefore logged the variables for income and lodging expenditures and included them in the model, with a dummy variable to control for those who did not spend any money on lodging (day-trippers). The negative yet insignificant coefficients on the 'No lodging cost' and 'Mean lodging cost' variables imply the lack of an effect of trip expenditures on the likelihood of continuing beach visits. Higher income, however, may reduce that likelihood, as the effect is borderline significant $(p=0.069)$. Interestingly, logistic modeling results (not presented here) further reveal that beachgoers with higher income are significantly less likely $(p=0.041)$ to visit a beach not typically or never before visited, to see a wind farm. Thus, individuals who have higher incomes are less likely to visit both familiar and unfamiliar beaches with offshore wind farms, all else constant.

The variable measuring whether a respondent has previously seen a wind turbine (land or sea-based) has a positive yet insignificant coefficient. The odds of continuing to visit a Delaware beach increase significantly, by a factor of 9.2 (since the logit is the log of the odds, the exponential of the logit provides the odds of the outcome - in this case, a visit to either the same beach or another beach in Delaware - and thus exp $(2.221)=9.2$ [49]), when the respondent is below 30 years of age, holding all else constant. In a survey examining the visual impacts of offshore wind turbines, Bishop and Miller [37] found a similar age effect, with the youngest age group having significantly more positive responses than the oldest. This effect may be attributable to the overall negative correlation between increasing age and environmental concern [50]. Younger generations also may not have as much of an attachment to place, and further, may be more willing to embrace, or at least be less risk averse to, new technology.

The boardwalk survey variable is the most significant and influential predictor in the model, with the odds of continuing to visit a Delaware beach increasing by a factor of about ten if the respondent was sampled on the boardwalk, as opposed to on the beach (Cape Henlopen State Park, discussed next, is the only exception). This finding is intuitive, considering that tourists on the boardwalk presumably tend to be less focused on the seascape than those on the beach, and instead more focused on other beach area attractions such as shops and restaurants.

Similarly, the odds of visiting a Delaware beach significantly increase by a factor of about eight if the respondent was sampled at Cape Henlopen State Park rather than at the other beach locations, all else constant. Given that out-of-state visitors to Delaware's three state parks (Cape Henlopen, Delaware Seashore, and Fenwick Island) seek more natural beach characteristics than those found at more developed Delaware beaches (for example, Rehoboth, Bethany, and Dewey beaches) we analyzed the routes that tourists most likely traversed from their points of origin to reach Cape Henlopen, Delaware's northernmost state park. If distance traveled affected the beach choice decision, Delaware Seashore State Park could serve as a convenient substitute for Cape Henlopen. Cape Henlopen, however, differs from Delaware Seashore (and Fenwick Island) State Park in that those visiting it are less likely doing so solely for the beach experience. Compared to the other Delaware state parks, Cape Henlopen offers a more diverse range of outdoor activities for visitors, including 
hiking and biking along forest trails and ponds, whereas the other state parks, primarily (if not exclusively) attract tourists who visit specifically to sunbathe, swim, surf fish, etc. The significantly greater likelihood of visiting Cape Henlopen if a wind farm was built $10 \mathrm{~km}$ offshore, compared to the other Delaware beaches, may therefore be attributable to the lack of adequate, proximate substitutes to Cape Henlopen, given its unique and diverse natural amenities.

Last, for each additional 16 to 17 year-old in a family, the odds of visiting either the same beach with turbines $10 \mathrm{~km}$ from shore or another beach in Delaware increase by a factor of 3.45, all else held constant. Contrastingly, neither the number of children (from 0 to 15 years) nor the presence of any children (yes or no) in a given household was significant (neither variable was included in the final model). Older teenagers may have strong beach preferences irrespective of whether a wind farm is present (for example, they may have preferences for non-beach amenities in the adjacent town or their teenage friends may vacation in the beach/town they are visiting) and their parents may not wish to override those preferences.

\subsubsection{Excluded Variables and Diagnostics Employed}

Neither sex nor education significantly influenced the likelihood of visiting a Delaware beach with a wind farm $10 \mathrm{~km}$ from shore. Similarly, due to their insignificance, none of the variables measuring either the frequency of beach visits (number of days spent visiting a US beach in the past year, number of days spent at a Delaware beach in the past year, and number of trips made to Delaware that included a beach visit in the past 5 years) or the duration or timing of the present trip (number of days, number of nights, and weekend trip) were included in the model presented. Given Ladenburg's finding that attitude formation toward offshore wind power is closely associated with the frequency and type of beach visits [25], this finding may at first appear surprising. However, his study examined attitudes among Danish residents toward existing offshore wind farms, whereas none of the out-of-state tourists in this study have had any experience with offshore wind turbines, at least not along Delaware's coast.

Finally, a number of variables measuring attitudes toward and perceived effects of wind power were not included in the beach visitation model because those variables were endogenous. Endogeneity occurs when the relationship between the dependent variable and the specified independent variables is bidirectional, or simultaneous; in such cases, the variables in the model are jointly, or mutually, determined [51]. Additional endogenous variables excluded from the model are those measuring the desirability of beach amenities or features (presented in Table 3) as well as the perceived effect of wind power on climate change.

The VIF (Variance Inflation Factor) diagnostic was used to formally test for multicollinearity among the explanatory variables specified in the offshore wind beach visitation model. None was found.

\subsection{Tourism Economic Development Associated with Offshore Wind Farms}

In isolation, the results presented so far-that visible wind farms would likely deter some visitors - suggest a strong argument for locating offshore wind turbines at distances greater than $16 \mathrm{~km}$ from shore, if not out of sight. However, the results have not yet accounted for any increase in beach 
visitation that may result from a wind farm. Table 8 illustrates the potential benefit to beach tourism resulting from an offshore wind farm. Approximately $66 \%$ of out-of-state tourists say they would be very or somewhat likely to visit a beach they do not typically visit, at least once, if a wind development were to be built $10 \mathrm{~km}$ offshore. This visitation effect is stronger among Delaware residents, sampled in 2006, with $84 \%$ likely to visit such a beach [8]. This discrepancy could be due to proximity, pride, place attachment or other local factors.

In any case, these results demonstrate a strong attraction to a beach with visible turbines. Importantly, the number attracted is a majority of both Delaware residents and out-of-state tourists. Even among out-of state tourists the percentage attracted (66\%) is over twice the percentage reporting they would not visit the same beach $(26 \%)$ and more than nine times the percentage reporting they would switch to an out-of-state beach (7.2\%). Given the large percentage of visitors to Delaware beaches who indicate that they would likely visit a beach with a visible wind farm, one can surmise that some number of beachgoers who typically visit beaches in neighboring Maryland and New Jersey, and regional travelers not currently visiting any Delaware beach (and thus not in our sample), would also be inclined to visit such a beach. Further, although the question asked about visiting "at least once," some first-time visits could spark additional trips to the same beach, especially if attractive beach amenities are available, or if tourists should travel with more than one group of relatives or friends [8].

Thus, despite the uncertainties regarding reported behavior and whether a question about "at least one visit" can be compared with potentially ongoing avoidance of wind turbines, the attractive effect appears to be stronger than the avoidance effect. That is, although evidence is not firm, there is a good chance that a wind development $10 \mathrm{~km}$ offshore would increase beach tourism rather than reduce it.

The question above about the attractive effect of an offshore wind farm does not consider that entrepreneurs or the local tourism industry may try to make it a tourism attraction. We thus asked about one such possibility - a boat tour of the wind development. Forty-four percent of out-of-state beachgoers report they would likely pay to take a boat tour of an offshore wind facility (Table 8).

Table 8. Likelihood of visiting a new or different beach at least once to see an offshore wind farm located $10 \mathrm{~km}$ from shore or of taking a boat tour.

\begin{tabular}{lcc}
\hline Response & $\begin{array}{c}\text { New or different beach } \\
(\mathbf{n = 4 9 5 ) *}\end{array}$ & $\begin{array}{c}\text { Boat tour } \\
(\mathbf{n = 1 , 0 1 0})\end{array}$ \\
\hline Very likely & $35.5 \%$ & $15.9 \%$ \\
Somewhat likely & $30.2 \%$ & $28.5 \%$ \\
Somewhat unlikely & $15.6 \%$ & $23.1 \%$ \\
Very unlikely & $18.6 \%$ & $32.4 \%$ \\
\hline
\end{tabular}

* The number of observations in the "New or different beach" column for the whole sample is essentially halved because half of the surveys specified the 10-km wind farm distance with this question and the other half the $22-\mathrm{km}$ wind-farm distance. We report the results here for the $10 \mathrm{~km}$ sample only, for comparability purposes. 
In sum, reported avoidance of beaches with offshore wind turbines:

- diminishes with greater turbine distance from shore;

- is less than avoidance of beaches with a fossil fuel power plant located the same distance inland;

- is less than reported attraction to them;

- is less than the number of beachgoers reporting they would likely pay to take a boat tour.

Given these results, we suggest that, as a novelty and a tourist attraction, an offshore wind farm could pave the way for new tourist activities and services, such as a visitor center and opportunities for marketing the offshore wind site beyond the state, in addition to offshore wind boat tours asked about in the survey [8].

\section{Conclusions}

Based on the contingent behavior findings of tourists' stated beach visitation, we would not advise developers of offshore wind to claim that there will be no negative impact on tourism. Some beachgoers report that they would avoid beaches with visible turbines, as one may anticipate from the general literature and industry perceptions. Considering that the reported avoidance effect diminishes with greater distance from shore, locating offshore wind turbines further out to sea would mitigate this outcome. Examining the avoidance question in isolation from other offshore wind farm tourism effects, however, would yield a misleading picture. We also find a reported avoidance of beaches with a fossil fuel power plant located the same distance inland, and that avoidance is stronger than the avoidance of offshore wind. More important is the presence of a countervailing effect-respondents' attraction to both offshore wind boat tours and to beaches themselves in order to see wind turbines is substantially greater than reported avoidance of beaches with visible wind turbines.

\section{Acknowledgements}

The authors wish to thank the anonymous reviewers for their insightful comments on the manuscript. Further, both the survey questions and this article have benefited from comments received from George Parsons and Jonathan Lilley. We are also grateful for the contributions of Jesse Fernandes, Andrew Krueger, Jacqueline Piero, Joana Flor Tavares, Phil Whitaker, Kelley Appleman, Amardeep Dhanju, and Peter Edwards for their assistance with survey design and development, pretesting, administration, and/or data entry. Diane and William Hanson's hospitality in providing accommodations for us during our survey sampling and collection efforts was very helpful and most appreciated. We also thank the Cape Wind developer, Energy Management, Inc., for granting us permission to use the photo simulations, as well as Delaware/NOAA Sea Grant for funding this research.

This article was prepared under award NA09OAR4171041 from the National Oceanic and Atmospheric Administration (NOAA) US Department of Commerce. The statements, findings, conclusions, and recommendations are those of the authors and do not necessarily reflect the views of NOAA or the Department of Commerce. 


\section{References}

1. Toepfer, K. Foreword: Signposts to Sustainability. In Wind Energy in the 21st Century: Economics, Policy, Technology and the Changing Electric Industry; Redlinger, R.Y., Andersen, P.D., Morthorst, P.E., Eds.; Palgrave Macmillan: Houndmills, UK, 2002.

2. American Wind Energy Association. Wind Energy Grows by Record 8,300 MW in 2008: Smart Policies, Stimulus Bill Needed to Maintain Momentum in 2009; AWEA Newsroom: Washington, DC, USA, 2009; Available online: http://www.awea.org/newsroom/releases/wind_energy_ growth2008_27Jan09.html/ (accessed on 26 September 2009).

3. US and China in Race to the Top of Global Wind Industry; Global Wind Energy Council: Brussels, Belgium, 2009; Available online: http://www.gwec.net/index.php?id=30\&no_cache=1\&tx_ttnews [tt_news] $=177 \& t x \_t t n e w s[$ backPid] $=4 \& c H a s h=04 f d c 8 c 00 \mathrm{a} /$ (accessed on 26 September 2009).

4. Roach, J. U.S. Leads World in Wind-Power Growth. National Geographic News, April 21, 2008; Available online: http://news.nationalgeographic.com/news/2008/04/080421-wind-power.html/ (accessed on 26 September 2009).

5. Wiser, R.; Bolinger M. Annual Report on U.S. Wind Power Installation, Cost, and Performance Trends: 2006; Technical Report No.: DOE/GO-102007-2433; National Renewable Energy Laboratory: Washington, DC, USA, 2007; pp 1-23.

6. Kempton, W.; Archer, C.L.; Dhanju, A.; Garvine, R.W.; Jacobson, M.Z. Large CO2 Reductions via Offshore Wind Power Matched to Inherent Storage in Energy End-uses. Geophys. Res. Lett. 2007, 34, L02817.

7. Firestone, J.; Kempton, W. Public Opinion About Large Offshore Wind: Underlying Factors. Energ. Policy 2007, 35, 1584-1598.

8. Firestone, J.; Kempton, W.; Krueger, A. Public Acceptance of Offshore Wind Power Projects in the USA. Wind Energy 2009, 12, 183-202

9. Kempton, W.; Firestone, J.; Lilley, J.; Rouleau, T.; Whitaker, P. The Offshore Wind Power Debate: Views from Cape Cod. Coast. Manage. 2005, 33, 119-149.

10. Parsons, G.R.; Massey, D.M., A Random Utility Model of Beach Recreation. In The New Economics of Outdoor Recreation; Edward Elgar Publishing: Cheltenham, UK, 2003; pp. 241-267.

11. Houston, J.R. The Economic Value of Beaches-A 2008 Update. Shore Beach 2008, 76, 22-26.

12. How Important is Tourism to Delaware? Global Insight Inc.: Lexington, MA, USA, February 1, 2008; pp. 1-34. Available online: http://www.dedo.delaware.gov/information/tourism/DelawareTSA-final_Feb2008.pdf (accessed on 26 September 2009).

13. How Important is Tourism in Delaware? The Tourism Satellite Account Perspective; Global Insight Inc.: Lexington, MA, USA, June 9, 2005; pp. 1-38. Available online: http://www. visitsoutherndelaware.com/media/2005_Economic_Impact_Global_Insight_Study.pdf (accessed on 26 September 2009). 
14. Kent, L.K.; Jones, C. The Economic Effects of a Five Year Nourishment Program for the Ocean Beaches of Delaware, Updated; Report No. 2006-102; Chrysalis Consulting Inc.: Alexandria, VA, USA, 2007; pp. 1-50.

15. Krueger, A.D. Valuing Public Preferences for Offshore Wind Power: A Choice Experiment Approach. Doctoral Dissertation; University of Delaware: Newark, DE, USA, Fall, 2007.

16. Dudleston, A. Public Attitudes Towards Wind Farms in Scotland: Results of a Residents Survey; The Scottish Executive Central Research Unit: Edinburgh, UK 2000; pp. 1-40.

17. Kannen, A., The Need for Integrated Assessment of Large-scale Offshore Wind Farm Development. In Managing European Coasts: Past, Present and Future, Vermaat, J.; Bouwer, L.; Turner, K.; Salomons, W., Eds. Springer: Berlin, Germany, 2005; pp. 365-378.

18. Harrington, M. Wind Power's Payoff in Denmark: It's a Global Leader in the Technology, and Turbines are a Common Sight, but Criticism and Challenges Persist. Newsday, October 30, 2006.

19. Kuehn, S. Sociological Investigation of The Reception of Horns Rev and Nysted Offshore Wind Farms In the Local Communities; Annual Status Report 2003; Elsam Engineering: Fredericia, Denmark, 2005; pp. 1-25.

20. British Wind Energy Association The Impact of Wind Farms on the Tourist Industry in the UK; London, UK, 2006; pp. 1-23.

21. Cook, G. Renewable Energy Policy in Denmark - An Introduction; Scottish Parliament Information Centre (SPICe): Edinburgh, UK, 2004; pp. 1-13.

22. Firestone, J.; Kempton, W.; Krueger, A.; Loper, C. E. Regulating Offshore Wind Power and Aquaculture: Messages from Land and Sea. Cornell J. Law Public Policy 2005, 14, 71-111.

23. Santora, C.; Hade, N.; Odell, J. Managing Offshore Wind Developments in the United States: Legal, Environmental and Social Considerations Using a Case Study in Nantucket Sound. Ocean Coast. Manage. 2004, 47, 141-164.

24. Institut für Tourismus- und Bäderforschung in Nordeuropa (N.I.T.). Touristische Effekte von On- und Offshore- Windkraftanlagen in Schleswig-Holstein; Kiel, Germany, 2000; pp. 1-4.

25. Ladenburg, J. Attitudes towards Offshore Wind Farms - the Role of Beach Visits on Attitude and Demographic and Attitude Relations. Energ. Policy 2009, (in press).

26. Soerensen, H.C.; Hansen, L.K.; Hansen, R.; Hammarlund, K. European Thematic Network on Wave Energy, Public Acceptability, Final Report; NNE5-1999-00438, WP 3.4; 2003; pp. 1-23.

27. Devlin, E. Factors Affecting Public Acceptance of Wind Turbines in Sweden; Master's thesis, Lund University: Lund, Sweden, 2002.

28. Dalton, G.J.; Lockington, D.A.; Baldock, T.E. A Survey of Tourist Attitudes to Renewable Energy Supply in Australian Hotel Accommodation. Renewable Energy 2008, 33, 2174-2185.

29. Strachan, P.A.; Lal, D.; von Malmborg, F. The Evolving UK Wind Energy Industry: Critical Policy and Management Aspects of the Emerging Research Agenda. Eur. Environ. 2006, 16, 1-18.

30. NFO WorldGroup Investigation into the Potential Impact of Wind Farms on Tourism in Wales, Summary Report; Project 013479; Edinburgh, UK, 2003; pp. 1-21.

31. Lieberman Research Group; Mills, D.; Rosen, H. New Jersey Shore Opinions About Off-Shore Wind Turbines; Great Neck, NY, USA, 2006; pp. 1-33. 
32. Aitchison, C. Fullabrook Wind Farm Proposal, North Devon: Evidence Gathering of the Impact of Wind Farms on Visitor Numbers and Tourist Experience; University of the West of England: Bristol, UK, 2004; pp. 1-26.

33. Strachan, P.A.; Lal, D., Wind Energy Policy, Planning and Management Practice in the UK: Hot Air or a Gathering Storm? Reg. Stud. 2004, 38, 551-571.

34. Firestone, J.; Kempton, W.; Krueger, A. Delaware Opinion on Offshore Wind Power, Final Report; University of Delaware: Newark, DE, USA, 2008; pp. 1-66.

35. Dillman, D. A., Mail and Internet Surveys: The Tailored Design Method. 2nd ed.; John Wiley \& Sons: Hoboken, NJ, USA, 2007.

36. An Assessment of the Potential Costs and Benefits of Offshore Wind Turbines; Global Insight Inc.: Lexington, MA, USA, 2008; pp. 1-102.

37. Bishop, I.D.; Miller, D.R. Visual Assessment of Off-shore Wind Turbines: The Influence of Distance, Contrast, Movement and Social Variables. Renewable Energy 2007, 32, 814-831.

38. Grijalva, T.C.; Berrens, R.P.; Bohara, A.K.; Shaw, W.D. Testing the Validity of Contingent Behavior Trip Responses. Amer. J. Agr. Econ. 2002, 84, 401-414.

39. Carson, R.T.; Hanemann, W.M., Contingent Valuation. In Handbook of Environmental Economics: Valuing Environmental Changes, Maler, K.G.; Vincent, J.R.; Eds.; Elsevier B.V.: Amsterdam, Netherlands, 2005; Volume 2, pp. 821-936.

40. Thur, S.M. Valuing Recreational Benefits in Coral Reef Marine Protected Areas: An Application to the Bonaire National Marine Park; Doctoral Dissertation, University of Delaware, Newark, DE, USA, 2003.

41. Southern Delaware Tourism, Beaches, Bays, and Waterways; The Official Convention \& Visitors Bureau of Sussex County Delaware: Georgetown, DE, USA, 2008. Available online: http://www. visitsoutherndelaware.com/Beaches_Bays_and_Waterways.htm (accessed on 26 September 2009).

42. 2007 Visitor Profile Study: Sussex County; Delaware Economic Development Office: Dover, DE, USA, 2008; pp. 1-17.

43. Falk, J.M.; Graefe, A.R.; Suddleson, M.E. Recreational Benefits of Delaware's Public Beaches: Attitudes and Perceptions of Beach Users and Residents of the Mid-Atlantic Region; Technical Report No. DEL-SG-05-94; University of Delaware, Sea Grant College Program: Newark, DE, USA, 1994; pp. 1-40.

44. Ladenburg, J. Stated Public Preferences for On-land and Offshore Wind Power Generation-A Review. Wind Energy 2009, 12, 171-181.

45. Logan, J.; Kaplan, S.M. Wind Power in the United States: Technology, Economic, and Policy Issues; RL34546; Congressional Research Service: Washington, DC, USA, 2008; pp. 1-49.

46. Krueger, A.; Firestone, J.; Parsons, G. Preferences for Offshore Wind Power Development: A Choice Experiment Approach. Land Econo. (under review)

47. Jarvis, C.M. An Evaluation of The Wildlife Impacts of Offshore Wind Development Relative to Fossil Fuel Power Production; Master's thesis, University of Delaware: Newark, DE, USA, 2005.

48. Lilley, M.B.; Firestone, J., Wind Power, Wildlife, and the Migratory Bird Treaty Act: A Way Forward. Environ. Law 2008, 38, 1167-1214. 
49. Long, J.S. Regression Models for Categorical and Limited Dependent Variables; Sage Publications: Thousand Oaks, CA, USA, 1997; Volume 7.

50. Booth, D.E. Searching for Paradise: Economic Development and Environmental Change in the Mountain West; Rowman \& Littlefield Publishers: Lanham, MD, USA, 2002.

51. Gujarati, D.N. Basic Econometrics. 4th ed.; McGraw-Hill/Irwin: New York, NY, USA, 2003.

(C) 2010 by the authors; licensee Molecular Diversity Preservation International, Basel, Switzerland. This article is an open-access article distributed under the terms and conditions of the Creative Commons Attribution license (http://creativecommons.org licenses/by/3.0/)./ 